“(C) 2015 IEEE. Personal use of this material is permitted. Permission from IEEE must be obtained for all other uses, in any current or future media, including reprinting/republishing this material for advertising or promotional purposes, creating new collective works, for resale or redistribution to servers or lists, or reuse of any copyrighted component of this work in other works." 


\title{
A Novel Claw Pole Permanent Magnet Motor with SMC and Ferrite PM
}

\author{
Chengcheng Liu ${ }^{1}$, Jianguo Zhu ${ }^{2}$, Youhua Wang ${ }^{1}$, Gang Lei ${ }^{2}$, Youguang Guo ${ }^{2}$, Xiaojing Liu ${ }^{1}$ \\ ${ }^{1}$ Province-Ministry Joint Key Laboratory of EFEAR, Hebei University of Technology, Tianjin, China \\ ${ }^{2}$ School of Electrical, Mechanical and Mechatronic System, University of Technology, Sydney, Sydney, Australia \\ E-mail: Chengcheng.Liu@uts.edu.au
}

\begin{abstract}
This paper proposes a novel low-cost claw pole permanent magnet motor with soft magnetic composite (SMC) core and ferrite permanent magnet (PM). Since the ferrite PM is much cheaper than the rare earth PMs, the material cost of this motor can be reduced greatly. And the special spoke type rotor can make the ferrite PM produce very high air gap flux density in this motor. By using the SMC material, the claw pole stator and rotor core can be manufactured very easily. A $675 \mathrm{~W} 1.8 \mathrm{Nm}$ claw pole motor is designed to replace the conventional permanent magnet synchronous motor (PMSM) in a refrigerator compressor. The finite element method (FEM) package ANSOFT and simplified magnetic network method are used to calculate the electromagnetic parameters of this motor. And the equivalent electric circuit is developed to predict the motor performance.
\end{abstract}

Index Terms-Low-cost claw pole permanent magnet motor, soft magnetic composite, ferrite permanent magnet, simplified magnetic network method.

\section{INTRODUCTION}

Soft magnetic composite (SMC) material is a relatively new soft magnetic material that has many advantages over the conventional silicon steels. The main advantages of SMC are its magnetic isotropy and powder metallurgy characteristic; various complex electromagnetic devices can be manufactured by this material. With the high production, low pressure in the molding, the manufacture cost of the motor with SMC core will be reduced greatly in a commercial production [1]. On the other hand, the disadvantages of SMC are that its permeability is quite low and its core loss is high at low frequencies. Hence, the motor with SMC core may not meet the high performance drive requirements such as the electrical vehicle drive system. These characteristics have determined that the motor with SMC core should be designed with the permanent magnet (PM) excitation and it should be utilized in the low-cost applications.

During last decades, various electrical motors with SMC core have been developed. Compared with other motor topologies, the torque density of claw pole/transverse flux motor is relatively higher. The claw pole/transverse flux motors are two successful examples in the SMC motors [2]-[4]. These motors with SMC core have all used the rare earth PMs to produce the PM flux linkage in the coil which make the material cost very high.

Among various permanent magnet materials, the ferrite PM is the cheapest one. However, the residual magnetic flux density of ferrite PM is very low, which is only $30 \%$ of that of the rare earth PMs. In order to replace the rare earth PM with ferrite $\mathrm{PM}$ in the permanent magnet synchronous motor (PMSM), the flux concentrating rotor is needed. Among the flux concentrating rotor topology, the spoke type is a famous one. Various researches have worked on improving the performance of the PMSM with ferrite PM during the last decades. In 2013, Kim et al. proposed a modified spoke type ferrite magnet motor. Compared with the traditional spoke type ferrite magnet motor, the main performances of this motor are improved except the efficiency [5]. In 2013, Petrov et al. analyzed the performance of an outer rotor PMSM with ferrite magnets, showing that the PMSM with ferrite magnet has lower performance than the PMSM with $\mathrm{NdFeB}$, but higher performance than induction machines [6]. Furthermore, the ferrite PM can produce PM torque in the PMSM, and it can also be used to produce the PM torque in the synchronous reluctance motor [7].

TABLE I

SPECIFICATIONS OF THE TARGET MOTOR

\begin{tabular}{|c|c|}
\hline Rated speed & $3600 \mathrm{rpm}$ \\
\hline Rated torque & $1.8 \mathrm{Nm}$ \\
\hline Rated power & $675 \mathrm{~W}$ \\
\hline Rated efficiency & $80 \%$ \\
\hline Maximum speed & $7200 \mathrm{rpm}$ \\
\hline Minimum speed & $1200 \mathrm{rpm}$ \\
\hline Maximum power & $900 \mathrm{~W}$ \\
\hline Supply voltage & $230 \mathrm{~V}$ \\
\hline Outer radius of the motor & $55 \mathrm{~mm}$ \\
\hline Axial length & $60 \mathrm{~mm}$ \\
\hline
\end{tabular}

The aim of this paper is to propose a novel low cost claw pole motor (CPM) with SMC core and ferrite PM. A $675 \mathrm{~W}$, $1.8 \mathrm{Nm}$ motor is designed for replacing the PMSM with rare earth PM in the home applications. The requirements for the target motor are listed in Table I. Simplified equivalent magnetic network method (SEMNM) and finite element method (FEM) package ANSOFT are used to analyze the electromagnetic parameters of this motor.

\section{TOPOLOGY AND Dimensions OF THE CPM WITH SMC CORE AND FERRITE PM}

\section{A. Topology}

Fig. 1 shows the 3D view of one disk of the CPM. The complete CPM is composed of three disks that have 120 electrical degrees shift with each other. As shown in Fig. 1, the 
disk of CPM has a stator, several ferrite PMs, a rotor core and a shaft. As there are 12 ferrite PMs, the motor has 12 poles. In order to improve the motor performance, the special flux concentrating structure is used as shown in this figure. The concentrated global armature coil is located in the stator slot.

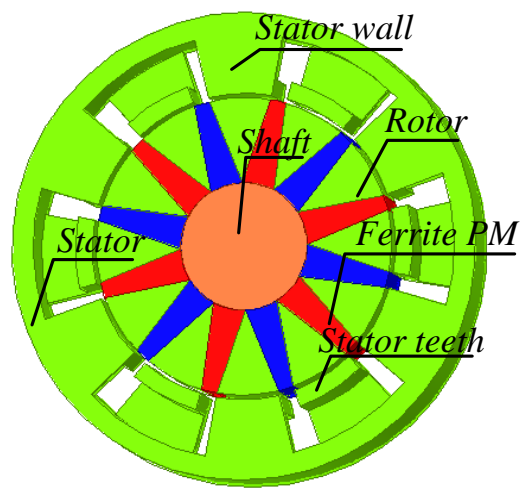

Fig. 1. Topology of the proposed motor

In this motor, all the effective magnetic parts are manufactured by the SMC - SOMALOY ${ }^{\mathrm{TM}} 500$, specifically the stator teeth. The PMs are of the ferrite type and the residual flux density is $0.4 \mathrm{~T}$ and the coercive force is $300 \mathrm{kA} / \mathrm{m}$.

\section{B. Dimensions of the motor}

Table II lists the major dimensions of the proposed motor. Considering that the permeability of SMC is quite low, increasing pole pairs will increase the magnetic reluctance of each part in the motor. On the other hand, increasing pole pairs in the claw pole motor will increase the flux leakages of the global winding. Finally, the number of pole pairs of this motor is chosen as 6. In this paper, the stator wall is defined as the part that connects the stator yoke and the stator teeth, as shown in Fig. 1.

TABLE II

DIMENSIONS OF THE CPM

\begin{tabular}{|c|c|}
\hline Outer radius of the stator & $55 \mathrm{~mm}$ \\
\hline Inner radius of the stator & $36 \mathrm{~mm}$ \\
\hline Thickness of the stator yoke & $5 \mathrm{~mm}$ \\
\hline Thickness of the stator wall & $5 \mathrm{~mm}$ \\
\hline Height of the stator tooth & $4 \mathrm{~mm}$ \\
\hline Air gap length & $1 \mathrm{~mm}$ \\
\hline Out radius of the rotor & $35 \mathrm{~mm}$ \\
\hline Inner radius of the rotor & $15 \mathrm{~mm}$ \\
\hline Number of pole pairs & 6 \\
\hline Axial length of the motor & $60 \mathrm{~mm}$ \\
\hline Number of coils per phase & 80 \\
\hline Material of the stator and rotor & SOMALOY \\
& 500 \\
\hline Material of the PM & Ferrite magnet \\
\hline
\end{tabular}

\section{Simplified EQUiVAlENT MAGNETIC NETWORK MODEL FOR THE PROPOSED MOTOR}

SEMNM is a simple way to analyze the electromagnetic parameters of the CPM. Compared with the magnetic circuit method, the magnetic network can calculate the motor parameter more precisely. On the other hand, compared with the FEM, using the SEMNM can save much computational time.

\section{A. Basic electromagnetic parameters deduced by the SEMNM}

Fig. 2 illustrates the SEMNM model of this motor. In order to make the model precise, each ferrite PM is divided into two parts. In this model, the resistance represents the magnetic reluctance and the current source represents magnetic flux of the PM. $R_{s y}$ represents the magnetic reluctance of stator yoke, $R_{s t}$ represents the magnetic reluctance of stator tooth, $R_{\text {gap }}$ represents the magnetic reluctance of air gap, $R_{r t 1}$ and $R_{r t 2}$ represent the magnetic reluctance of rotor, and $R_{p m 1}$ and $R_{p m 2}$ represent the magnetic reluctance of permanent magnet. The $\mathrm{PHI}_{p m}$ represents the magnetic flux of permanent magnets. By analyzing the magnetic network model, the main flux of each part can be calculated. In this motor, the peak value of air gap flux is $1.16 \mathrm{e}^{-4} \mathrm{~Wb}$, and the stator yoke flux is $5.8 \mathrm{e}^{-4} \mathrm{~Wb}$. The flux density of air gap is $0.405 \mathrm{~T}$, and the flux density of stator yoke is $0.58 \mathrm{~T}$.

By using the current excitation in this model, the inductance $\mathrm{L}$ can be calculated by

$$
L=\frac{\varphi_{I+P M}-\varphi_{P M}}{I}
$$

where $\varphi_{\mathrm{I}+\mathrm{PM}}$ is the flux linkage produced by the armature current and PM, and $\varphi_{\mathrm{PM}}$ the flux linkage produced by the PM only. The inductance is calculated as $2.3 \mathrm{mH}$

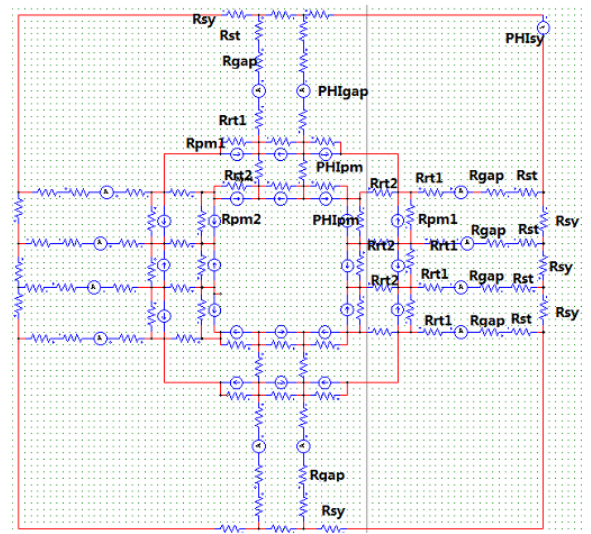

Fig. 2. Simplified magnetic network model for the motor

\section{B. Performance prediction by SEMNM}

In the PMSM, the electromagnetic torque is composed of two parts. One is the magnetic torque produced by the permanent magnet flux linkage and the other is the reluctance torque produced by the difference between the d-axis inductance and q-axis inductance. In this motor, the reluctance torque will be neglected. As the magnetic flux of the motor can be calculated by the SEMNM, the flux linkage per phase equals to the number of coil turns multiplied by the magnetic flux of each coil, and it can be represented as 


$$
\lambda_{p m}=k_{l} N_{c o i l} N_{r} \phi_{g a p}
$$

where $\lambda_{p m}$ is the PM flux linkage per phase, $k_{l}$ is the leakage coefficient, $N_{\text {coil }}$ is the number of phase coil turns, $N_{r}$ is the number of pole pairs, and $\Phi_{\text {gap }}$ is flux per coil. The back electromotive force (EMF) $E_{m}$ can be expressed as

$$
E_{m}=\omega_{e} \lambda_{p m}=N_{r} \omega_{m} \lambda_{p m}
$$

where $\omega_{e}$ is the electrical angular speed, and $\omega_{m}$ is the mechanical angular speed. The electromagnetic power $P_{e m}$ can be expressed as

$$
P_{e m}=\frac{m}{2} E_{m} I_{m}
$$

where is the number of phases.

The electromagnetic torque $T_{e m}$ can be expressed as

$$
T_{e m}=\frac{P_{e m}}{\omega_{m}}=\frac{m}{2} N_{r} \lambda_{p m} I_{m}
$$

The flux linkage of the phase coil is $0.028 \mathrm{~Wb}$, and the no load back EMF of phase coil is $61.2 \mathrm{~V}$ at the rated speed of $3600 \mathrm{rpm}$. Hence, according to (5), the electromagnetic torque is $1.8 \mathrm{Nm}$ at the rated current.

\section{Performance Validation by Finite Element METHOD}

Though the simplified magnetic network method can predict the motor performance initially, the accurate performance should be validated by using the FEM package ANSOFT. In this part, all the parameters predicted by the magnetic network method will be validated by the ANSOFT. The flux density, flux linkage, back EMF and electromagnetic torque will be analyzed.

In the performance prediction by ANSOFT, the complete one disk FEM model is built and the nonlinear magnetization curve of SMC is considered.

\section{A. Flux density analysis}

Fig. 3 shows the air gap flux density at the radial direction. It can be seen that the maximum air gap flux density is $0.42 \mathrm{~T}$. For comparison, in the simplified magnetic network model, the maximum air gap flux density is $0.405 \mathrm{~T}$.

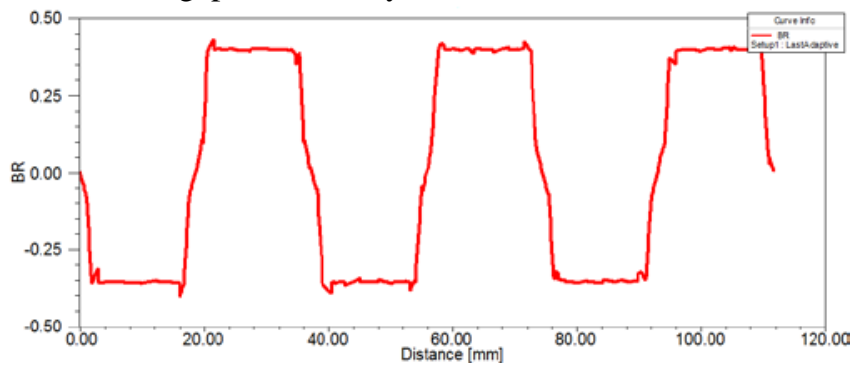

Fig. 3. Air gap flux density of the motor in the radial direction

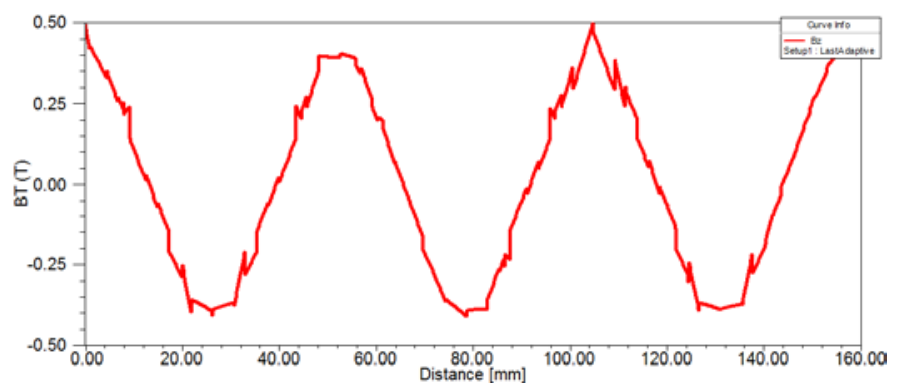

Fig. 4. Stator yoke flux density of the motor

Fig. 4 illustrates the flux density at the tangential direction in the stator yoke. It shows that the maximum flux density of the stator yoke at the no load is $0.5 \mathrm{~T}$. For comparison, in the magnetic network method, the value is $0.58 \mathrm{~T}$.

\section{B. Flux linkage and back EMF analysis}

EMF is produced in the armature coil as the rotor rotates. By differentiating the flux linkage, the phase back EMF can be calculated. Fig. 5 shows the flux linkage per phase winding of the motor against the time, and Fig. 6 shows the back EMF of the phase winding when the rotor rotates at $3600 \mathrm{rpm}$. It can be seen from the figure that the magnitude of the flux linkage is $0.0316 \mathrm{~Wb}$, and the magnitude of the back EMF is $59 \mathrm{~V}$. It can also be seen that the back EMF has many harmonics.

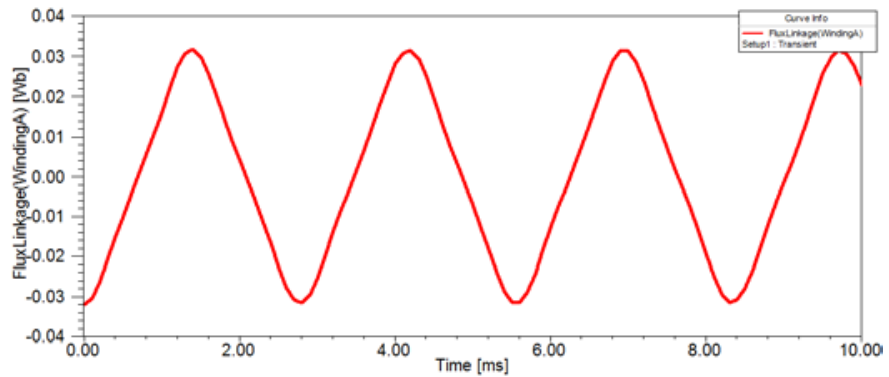

Fig. 5. Flux linkages of the motor

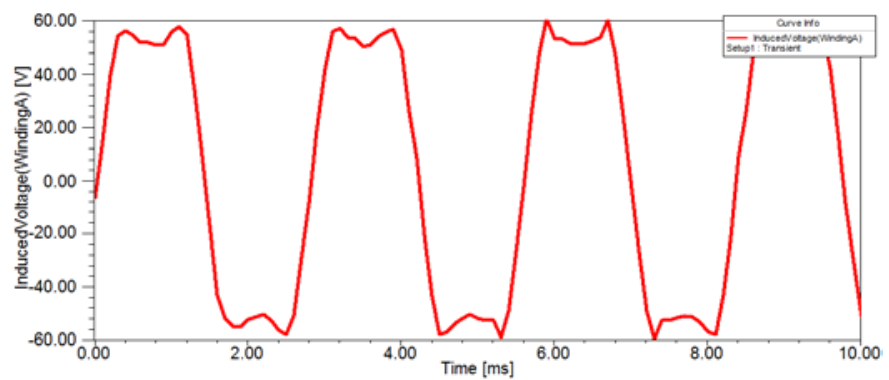

Fig. 6. Back EMF of the motor at the speed of $3600 \mathrm{rpm}$

\section{Performance Prediction of The Motor}

\section{A. Torque prediction}

In the performance prediction of a motor, the control method should be taken into consideration. In this paper, the condition that the d-axis current equals zero is applied. By using this control method, only the electromagnetic torque is worked out. Fig. 7 shows the equivalent electric circuit of this motor. 


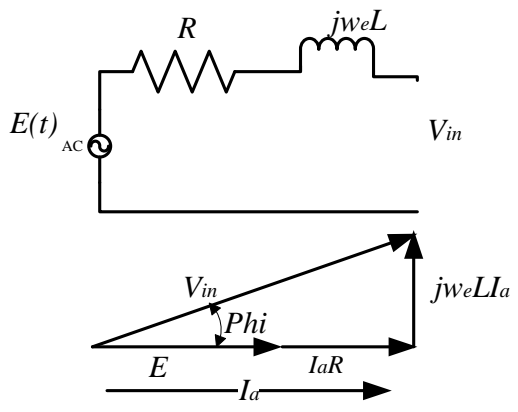

Fig. 7. Equivalent electric circuit of the motor

Based on this equivalent electrical circuit, the main relationships of the motor can be predicted by

$$
\begin{gathered}
V_{\text {in }}=\sqrt{\left(E+I_{a} R\right)^{2}+\left(\omega_{e} L I_{a}\right)^{2}} \\
P_{\text {in }}=3 V_{\text {in }} I_{a} \cos (P h i) \\
P_{\text {out }}=P_{\text {in }}-P_{\text {core }}-P_{\text {copper }}-P_{\text {mech }} \\
T_{\text {out }}=\frac{P_{\text {out }}}{\omega_{r}}
\end{gathered}
$$

where $V_{i n}$ is the input voltage, $E$ the back EMF, $I_{a}$ the armature current, $\omega_{e}$ the electric angular frequency, $L$ the inductance, $R$ the resistance, $P h i$ angle, $P_{\text {in }}$ input power, $P_{\text {out }}$ output power, $P_{\text {core }}$ the core loss, $P_{\text {copper }}$ the copper loss, $P_{\text {mech }}$ the mechanical loss, $T_{\text {out }}$ the output torque, and $\omega_{r}$ the mechanical angular speed.

The output torque is illustrated in Fig. 8. It only shows the output torque of a single disk of the motor. Therefore, the output torque of the motor should be multiplied by 3 .

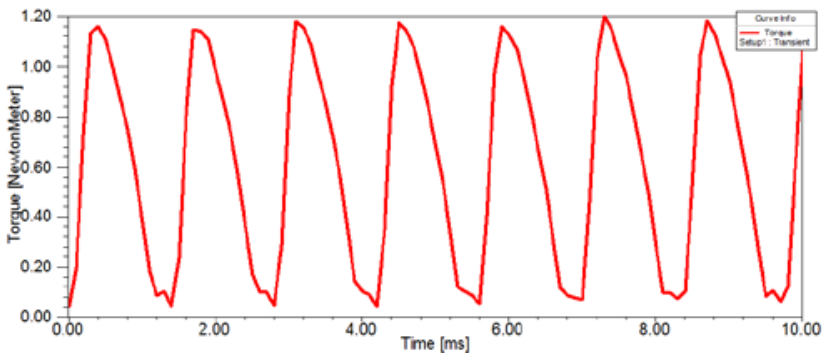

Fig. 8. Output torque of one disk with the phase current of $5 \mathrm{~A}$

\section{B. Efficiency analysis}

In the electric motor, the losses can be classified as core loss, copper loss and mechanical loss as expressed in (8). In the motor with SMC core, the core loss is the major part among these losses, and the mechanical loss is generally considered as $1 \%$ or $1.5 \%$ in the total output power. In the ANSOFT, the multi-frequency core loss curve is used to analyze the motor core loss. Its core loss of the single disk at the $3600 \mathrm{rpm}$ is plotted in Fig. 9. The copper loss can be estimated by

$$
P_{\text {copper }}=m R I_{a}^{2}
$$

where $R$ is the resistance, which can be calculated by the resistance formula. The resistance of this motor is $0.396 \mathrm{ohm}$. Hence, the copper loss is $14.85 \mathrm{~W}$. Then, the efficiency can be calculated by

$$
\eta=\frac{P_{\text {out }}}{P_{\text {out }}+P_{\text {mech }}+P_{\text {core }}+P_{\text {copper }}}
$$

The efficiency is calculated as $82 \%$ at the rated speed and rated power.

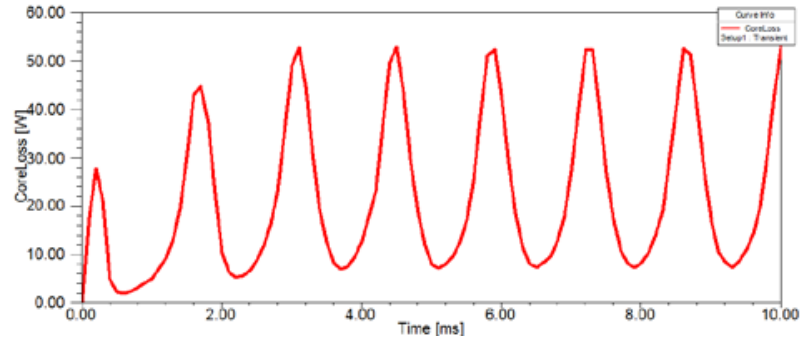

Fig. 9. Core loss prediction at the speed of $3600 \mathrm{rpm}$

The parameters of the CPM are listed in Table 3, which will be used to judge the motor performance.

TABLE III

BASIC PARAMETERS OF THE CPM

\begin{tabular}{|c|c|}
\hline Inductance & $2.3 \mathrm{mH}$ \\
\hline Resistance(phase) & $0.396 \mathrm{ohm}$ \\
\hline PM flux linkage & $0.0316 \mathrm{~Wb}$ \\
\hline EMF constant (phase) & $17.54 \mathrm{~V} / \mathrm{krpm}$ \\
\hline Torque constant & $0.252 \mathrm{Nm} / \mathrm{A}$ \\
\hline \multicolumn{2}{c}{$T_{\text {em }}=T_{c} I_{a}$} \\
$E_{m}=E_{c} \omega_{r}$
\end{tabular}

where $T_{e m}$ is the electromagnetic torque, $T_{c}$ the torque constant, $I_{a}$ armature current peak value, $E_{m}$ the back EMF, $E_{c}$ the EMF constant, and $w_{r}$ the mechanical angular speed.

\section{Cost evaluation}

In the motor with SMC core and ferrite magnets, the material cost and manufacture cost can be reduced greatly. Furthermore, in a motor with SMC core, the material cost takes the major part. Consequently, only the material cost is considered in this paper. The material cost is based on following material prices. The coil is considered to be AUD \$6 per kilogram, SMC is considered to be AUD \$1 per kilogram, and ferrite magnet is considered to be AUD \$2 per kilogram. The total materials cost of this motor is AUD \$9.8.

\section{CONCLUSION}

A novel claw pole PM motor with SMC core and ferrite PM is proposed and designed in this paper. By taking the PM flux concentrating rotor structure, the air gap flux density at the radial direction of this motor can reach $0.5 \mathrm{~T}$. Therefore, the cheap ferrite PM can replace the rare earth PM in this CPM, 
and the material cost of this motor is only AUD \$9.8. A $675 \mathrm{~W}$ 1.8 Nm CPM is designed and analyzed in this paper. With the help of SEMNM and FEM package ANSOFT, the magnetic parameters have been calculated. By applying the condition that the d-axis current equals 0 , the output torque is predicted to be $1.8 \mathrm{Nm}$, and the efficiency is predicted to be $82 \%$. It shows that this motor can meet the design targets.

\section{REFERENCES}

[1] Y. G. Guo, J. G. Zhu, and D. G. Dorrell, "Design and analysis of a claw pole permanent magnet motor with molded soft magnetic composite core,” IEEE Transactions on Magnetics, vol. 45, pp. 4582-4585, 2009.

[2] Y. G. Guo, J. G. Zhu, P. A. Watterson, and W. Wu, "Development of a PM transverse flux motor with soft magnetic composite core,” IEEE Transactions on Energy Conversion, vol. 21, pp. 426-434, 2006.

[3] Y. G. Guo, J. G. Zhu, P. A. Watterson, and W. Wu, "Comparative study of 3-D flux electrical machines with soft magnetic composite cores,"IEEE Transactions on Industry Applications, vol. 39, pp. 16961703, 2003.

[4] J. G. Zhu, Y. G. Guo, Z. W. Lin, Y. J. Li, and Y. K. Huang, "Development of PM transverse flux motors with soft magnetic composite cores," IEEE Transactions on Magnetics, vol. 47, pp. 43764383, 2011.

[5] S. I. Kim, J. Cho, S. Park, T. Park, and S. Lim, "Characteristics comparison of a conventional and modified spoke-type ferrite magnet motor for traction drives of low-speed electric vehicles," IEEE Transactions on Industry Applications, vol. 49, pp. 2516-2523, 2013.

[6] I. Petrov and J. Pyrhonen, "Performance of low-cost permanent magnet material in PM synchronous machines," IEEE Transactions on Industrial Electronics, vol. 60, pp. 2131-2138, 2013.

[7] S. Ooi, S. Morimoto, M. Sanada, and Y. Inoue, "Performance evaluation of a high-power-density PMASynRM with ferrite magnets," IEEE Transactions on Industry Applications, vol. 49, pp. 1308-1315, 2013. 